\title{
Os 70 anos da ONU e a agenda global para o segundo quindênio (2015-2030) do século XXI
}

\author{
José Eustáquio Diniz Alves*
}

\section{Introdução}

O ano de 2015 marca o septuagésimo aniversário da criação da Organização das Nações Unidas (ONU). Visando a tomada de decisões importantes para o desenvolvimento sustentável, a luta contra as mudanças climáticas e as crises humanitárias, foram construídos três grandes eventos para formatar a agenda internacional pós-2015: a Terceira Conferência Internacional sobre Financiamento para o Desenvolvimento (FpD3), em Addis Abeba, capital da Etiópia, de 13 a 16 de julho; a Cúpula do Desenvolvimento Sustentável da ONU, em Nova lorque, de 25 a 27 de setembro, para aprovação dos Objetivos de Desenvolvimento Sustentável (ODS); e a 21 a Conferência do Clima (Conferência das Partes, COP-21), em Paris, de 30 de novembro a 11 de dezembro, tendo como principal finalidade costurar um novo acordo global entre os países para diminuir a emissão de gases de efeito estufa e reduzir o ritmo de aumento do aquecimento global, objetivando limitar o aumento da temperatura global em $2^{\circ} \mathrm{C}$ até 2100 .

Dificilmente estas reuniões terão o sucesso esperado. Mas, como disse Dag Hammarskjöld - segundo secretário geral da entidade -, a ONU “Foi criada não para conduzir a humanidade para o céu, mas para salvá-la do inferno” (McGREAL, 2015, p. 1). Mesmo com todas as dificuldades e contradições do processo de negociação internacional, há, sem dúvida, um esforço bem intencionado para lidar com os principais desafios do mundo contemporâneo. Porém, a realidade mundial é complexa e a capacidade de governança é pequena. 0 objetivo deste texto é apresentar os principais pontos da agenda pós-2015 da ONU e fazer uma avaliação crítica dos três marcantes eventos do corrente ano.

\footnotetext{
*Escola Nacional de Ciências Estatísticas (Ence) do Instituto Brasileiro de Geografia e Estatística (IBGE), Rio de Janeiro-RJ, Brasil (jed_alves@yahoo.com.br).
} 


\section{Terceira Conferência Internacional sobre Financiamento para o Desenvolvimento (FpD3)}

O financiamento ao desenvolvimento, que é parte essencial do processo de Conferências das Nações Unidas e visa ampliar a capacidade de recursos financeiros para a cooperação internacional, iniciou-se em março de 2002, com a Primeira Conferência Internacional sobre Financiamento ao Desenvolvimento (FpD1), no México, objetivando formular recomendações sobre comércio internacional, ajuda oficial externa, investimento estrangeiro direto, redução da dívida, mobilização interna de recursos e estruturação financeira global eficaz. 0 Consenso de Monterrey, como ficou conhecido o documento assinado na ocasião, buscou incentivar uma nova era na cooperação econômica entre as nações desenvolvidas, em desenvolvimento e as instituições financeiras globais, tais como Fundo Monetário Internacional, Banco Mundial e Organização Mundial do Comércio. Na Conferência de Monterrey (2002), a questão da dívida externa dos países e a alta taxa de juros foram temas relevantes, como foi visto no protagonismo da Campanha Jubileu 2000, que buscava a reestruturação da dívida externa dos países endividados, e na campanha TTF -Taxação sobre Transações Financeiras (REIS, 2015).

Em 2008 foi realizada a segunda Conferência em Doha, que, assim como a primeira, contou com a participação de líderes empresariais, ministros, chefes de Estado e sociedade civil, além de autoridades dos organismos internacionais a fim de reafirmar as metas preestabelecidas na elaboração da Declaração de Doha, buscando assegurar o financiamento ao desenvolvimento. Porém, a segunda Conferência sobre Financiamento ao Desenvolvimento - FpD2 foi prejudicada pelo cenário de incerteza da crise internacional, após a quebra do banco Lehman Brothers.

A Conferência de Addis Abeba - FpD3 aconteceu em um momento em que o financiamento ao desenvolvimento requer uma cifra em torno de três trilhões de dólares, mas, em 2014, a ajuda oficial para o desenvolvimento e a filantropia global, juntas, somaram apenas 134 bilhões de dólares. Evidentemente, a Agenda de Ação de Adis Abeba (AAAA) não foi capaz de enfrentar as injustiças estruturais do sistema econômico financeiro global e de garantir o financiamento ao desenvolvimento e o combate ao aquecimento global no marco da Agenda Pós-2015. Segundo o Fórum Internacional das Plataformas Nacionais de ONGs:

A Agenda de Ação de Adis Abeba (AAAA) perdeu a oportunidade de enfrentar as injustiças estruturais no atual sistema econômico global e garantir que o financiamento ao desenvolvimento seja centrado nas pessoas e proteja o meio ambiente. Esta agenda não se dirige aos múltiplos desafios atuais do mundo, tampouco faz emergir a liderança, a ambição e as ações práticas necessárias. Ela mina os acordos feitos no Consenso de Monterrey e na Declaração de Doha e é quase totalmente desprovida de resultados implementáveis. Lamentamos que as negociações tenham diminuído a autoridade do Financiamento ao Desenvolvimento para tratar de questões sistêmicas internacionais em macroeconomia, finanças, comércio, impostos e políticas monetárias, e, ao mesmo tempo, que tenham falhado em redimensionar os recursos existentes e em comprometer 
novos recursos. A AAAA também é profundamente inadequada para dar sustentação aos Meios de Implementação operacionais para a Agenda de Desenvolvimento Pós-2015, expondo um abismo sem pontes existente entre a retórica das aspirações e a realidade das ações (FIP, 2015, p. 1).

Parece até ironia, mas não se pode deixar de destacar que a FpD3 começou quando a crise financeira da Grécia estava no auge, após duas semanas com os bancos fechados por falta de dinheiro. Se um país que pertence à União Europeia tem sérias dificuldades para conseguir financiamento, não é difícil imaginar os obstáculos dos países realmente pobres. Logo depois da Conferência de Adis Abeba, o mundo assistiu bestificado a crise migratória, sendo que a imagem do corpo do menino sírio Aylan Kurdi, de três anos, numa praia da Turquia, gerou comoção internacional diante da tragédia de milhares de refugiados que tentam chegar à Europa. De fato, as desigualdades entre os países estão atingindo níveis preocupantes. Há guerras e conflitos trágicos acontecendo, como na Síria, Iraque, Ucrânia, lêmen, Sudão, etc. Com isso, aumenta o número de migrantes e refugiados do Terceiro Mundo, que sofrem com as guerras locais, a pobreza e as mudanças climáticas. A raiz do problema está na pobreza, na falta de democracia e na insegurança em que vive grande parte das populações africanas, do Oriente Médio e da Ásia e na incapacidade de diversas nações em garantir o desenvolvimento econômico e humano justo.

Mas a crise tem um escopo mais amplo e nem mesmo os países ricos estão imunes às suas consequências. A consultoria Mackinsey (2015) publicou um relatório mostrando que a dívida global dos domicílios (famílias), governos, empresas e setor financeiro aumentou de US\$ 87 trilhões no quarto trimestre de 2000 para US\$ 142 trilhões no quarto trimestre de 2007 e para US\$ 199 trilhões no segundo trimestre de 2014. Em proporção do PIB, a dívida total ampliou-se de $246 \%$ para $269 \%$, entre 2000 e 2007 , e atingiu $286 \%$ em 2014 . Isso quer dizer que a economia internacional tem sido sustentada por uma bolha de crédito que vem crescendo de forma exponencial, chegando praticamente a 200 trilhões de dólares em meados de 2014, ou quase três vezes o valor do PIB mundial. Evidentemente esta dívida terá que ser paga em algum momento do futuro pelas atuais ou posteriores gerações. Portanto, são grandes as chances de uma enorme recessão global e pequenas as probabilidades de se conseguir um financiamento justo para os países pobres (DAVEY, 2015).

Devido às políticas monetárias expansionistas, jamais as taxas de juros internacionais foram tão baixas. Aparentemente este fato poderia ajudar a recuperação econômica mundial. Mas, como mostrou Herman Daly, uma taxa de juros mantida artificialmente baixa no longo prazo gera uma série de distorções na alocação dos fatores de produção e uma demanda agregada quase infinita que pode ser colocada em xeque pela elevação do preço dos recursos naturais e pela degradação ambiental. A desenfreada criação de crédito pelo sistema financeiro geralmente leva ao surgimento de bolhas e à quebradeira de bancos e empresas. Daly (2015) propõe mudar as regras do sistema financeiro para evitar o desmoronamento do "castelo de cartas" da criação de créditos artificiais: "O sistema bancário de reservas fracionárias suporta toda a estrutura, tipo Ponzi, da pirâmide financeira, e 
para escapar da instabilidade precisamos urgentemente mover em direção a um sistema bancário de reservas completo" (DALY, 2015, p. 1, tradução nossa).

Nas condições atuais, a manutenção de baixas taxas de juros pode elevar de maneira insustentável o endividamento das famílias e das empresas, enquanto o aumento das taxas de juros pode criar uma crise de liquidez que afete principalmente os países em desenvolvimento, dependentes de capital externo. Portanto, as perspectivas para o financiamento ao desenvolvimento no próximo quindênio não são nada boas. 0 Fundo Monetário Internacional (FMI) alertou, no início de outubro de 2015, em reunião realizada em Lima, Peru, para a possibilidade de uma fuga abrupta e expressiva de capital dos países emergentes. Na mesma reunião, o FMI reduziu as previsões de crescimento da economia internacional para 2015 e apontou uma recessão de 3\% para o Brasil e de 0,3\% para América Latina e Caribe. A ONG Oxfam divulgou estudo no final de setembro mostrando que existem 200 milhões de latino-americanos sob risco de voltar à situação de pobreza (ESCAMILLA, 2015).

Com o fim do ciclo das commodities, a conjuntura atual não parece favorável aos países emergentes. Como mencionado, a Conferência de Addis Abeba deveria ter articulado fontes de recursos e meios de implementação dos ODS no valor aproximado de 3 trilhões de dólares por ano durante o próximo quindênio. Todavia, isso não foi feito e será ainda mais difícil de ser realizado diante da possibilidade de uma nova crise internacional de dimensões desastrosas.

\section{Objetivos de Desenvolvimento Sustentável (ODS)}

O termo desenvolvimento sustentável entrou definitivamente na pauta internacional após a divulgação do Relatório Brundtland, intitulado Nosso futuro comum, publicado em 1987. Nos anos seguintes, a ideia de sustentabilidade incorporou, além da dimensão ambiental, os aspectos social e econômico. Em geral, o tripé do desenvolvimento sustentável pretende ser, concomitantemente, socialmente justo, economicamente inclusivo e ambientalmente responsável.

O sonho da efetivação da sustentabilidade, em suas três dimensões, encontrou uma janela de oportunidade para ser debatida na década de 1990, quando o mundo conseguiu realizar uma série de conferências globais no âmbito da Organização das Nações Unidas (ONU). O fim da Guerra Fria e a maior distensão internacional criaram um ambiente de maior governança, cooperação e de enfrentamento dos problemas nacionais e mundiais.

Todas estas conferências, que tiveram ampla participação de governos, empresas e sociedade civil, produziram vários documentos de dezenas de páginas, com uma lista enorme de propostas e reivindicações. Portanto, havia uma ampla e avançada agenda para orientar as políticas de ação do século XXI, mas não foi definida uma proposta de monitoramento do progresso a ser alcançado. Porém, em 2000, o secretário geral da ONU, Kofi Annan, promoveu a Cúpula do Milênio, em Nova Iorque, que criou os Objetivos de Desenvolvimento 
do Milênio (ODM), estabelecendo oito pontos a serem alcançados pelos diversos países do mundo até 2015, buscando incorporar alguns temas das agendas internacionais.

Assim, como mostraram Correa e Alves (2005), os ODMs foram fruto de pouca discussão e baixo envolvimento da sociedade civil, representando uma redução e simplificação da agenda dos anos 1990 , além de colocar uma "régua" muito baixa ${ }^{1}$ nos objetivos a serem implementados:

A inflexão de rota identificada na elaboração final do mapa dos ODMs não chega a ser surpreendente. A conjuntura geopolítica dos anos 2000 tem sido - como bem analisam o embaixador Gelson da Fonseca e Benoni Belli - marcada por um forte sentimento de 'frustração'. Esse clima decorre das promessas não cumpridas da primeira metade da década de 90, quando a agenda das Nações Unidas se pautava por um projeto bastante ambicioso de governança global solidária e justiça. Essa promessa, como bem sabemos, vem sendo solapada pelo unilateralismo imperial norteamericano, pós-2001, pelo recrudescimento dos conflitos internacionais e, conseqüentemente, pelo crescimento dos investimentos militares em detrimento do financiamento do desenvolvimento, para não mencionar a sobrevida do chamado 'fundamentalismo de mercado' como princípio, meio e fim da gestão macroeconômica (CORREA; ALVES, 2005, p. 177).

Embora ainda não se disponha de dados conclusivos para 2015, a ONU avalia que os ODMs devem atingir suas principais metas (UN, 2015). Sem querer entrar numa avaliação mais ampla, cabe destacar, para os objetivos deste texto, ${ }^{2}$ que a primeira versão dos ODMs ignorou completamente as questões populacionais e os direitos sexuais e reprodutivos. Na revisão de 2005, depois de muita pressão da sociedade civil, embora não tenha sido incorporado o tema dos direitos sexuais, foi acrescentada a meta "\# 5b. Alcançar, até 2015, o acesso universal à saúde reprodutiva". Esta meta já tinha sido aprovada na CIPD do Cairo e visava atender ao significativo montante de 222 milhões de mulheres, no mundo, sem acesso aos meios de regulação da fecundidade (OMS, 2014).

Os Objetivos de Desenvolvimento Sustentável (ODS) vieram na esteira dos ODMs, mas foram propostos como resolução da Conferência das Nações Unidas sobre Desenvolvimento Sustentável (Rio + 20), realizada em 2012. A agenda mundial aprovada conta com 17 objetivos, 169 metas e, até o momento, tem mais de 300 indicadores propostos para o seu seguimento. A definição oficial dos ODS, com o acordo sobre os objetivos e metas, ocorreu entre 25 e 27 de setembro, em Nova York, durante a Assembleia Geral deste ano, ${ }^{3}$ sendo que seu parágrafo 75 afirma que os objetivos e as metas deverão ser monitorados e revisados por um conjunto de indicadores globais, além de indicadores regionais e nacionais. A Comissão Estatística da ONU, encarregada da definição deste conjunto de indicadores, constituiu para esta atividade um grupo interagencial (IAEG) composto por especialistas,

\footnotetext{
${ }^{1}$ Adicionalmente, como mencionado por Cunha e Rodriguez-Vignoli (2009), devido à natureza dos ODMs, a concentração da população em áreas urbanizadas e, principalmente, a aglomeração em grandes metrópoles facilitam para a América Latina atingir as metas estabelecidas.

2 Uma avaliação mais detalhada dos objetivos e metas dos ODM pode ser encontrada em Carvalho e Barcellos (2014).

${ }^{3} 0$ documento oficial, intitulado “Transforming our world: the 2030 Agenda for Sustainable Development”, está disponível em 〈http://www.un.org/ga/search/view_doc.asp?symbol=A/RES/70/1\&Lang=E〉.
} 
o qual apresentará a proposta na $47^{\text {a }}$ sessão da Comissão, em março de 2016, para ser posteriormente enviada para a Comissão Econômica e Social e para a Assembleia Geral da ONU de 2016.

Importante destacar que, ao contrário dos ODMs, a definição dos objetivos, metas e indicadores dos ODS ocorreu com ampla e democrática participação de várias instituições, organizações da sociedade civil e especialistas. Este processo obviamente não acontece de maneira tranquila, visto que os interesses dos vários grupos envolvidos nem sempre vão na mesma direção. No caso específico da definição dos indicadores, foi considerado o processo iniciado ainda com a Comissão do Desenvolvimento Sustentável (CDS), ${ }^{4}$ criada logo após o acordo da Agenda 21, além do processo dos ODMs. Adicionalmente, é importante mencionar que a Comissão Estatística da ONU é composta pelos institutos de estatística oficiais dos países membros, que obviamente não possuem a expertise em todos os temas dos ODS. Dessa forma, as agências multilaterais, entre outras, foram chamadas para colaborar na apresentação da primeira lista a ser discutida, com a simples indicação de que cada meta poderia ter no máximo dois indicadores, mas sem nenhuma diretriz mais específica sobre a metodologia a ser seguida, a não ser que deveriam ser priorizados recortes de idade, sexo, situação urbana e rural e outras características relevantes, quando justificado. ${ }^{5}$ Assim, o primeiro rascunho divulgado pela Comissão de Estatística contém alguns indicadores repetidos dos ODMs, outros novos bem definidos, outros pessimamente definidos, indicadores simples, compostos, indicadores praticamente impossível de serem mensurados, etc., mas praticamente todos sem a definição exata de mensuração e fonte de dados (inexistência de metadados).

Segundo Cavenaghi (2015), um dos grandes problemas apresentados na lista de indicadores foi a definição inadequada de muitas metas. Algumas delas são tão específicas que praticamente correspondem ao próprio indicador a ser seguido; em outros casos, são tão amplas (quase a declaração de uma aspiração) que se torna muito difícil identificar a população de interesse e, ainda, em inúmeras vezes, apresentam várias dimensões do problema em questão, impossibilitando medir com apenas um ou dois indicadores a situação específica a ser monitorada.

Em um segundo momento, a Comissão de Estatística enviou esta lista aos institutos de estatística, para investigação sobre a viabilidade de construção dos indicadores propostos e apresentação de revisão dos mesmos, bem como aos organismos multilaterais. A proposta revista, a qual está em discussão neste momento, foi apresentada em 11 de

\footnotetext{
${ }^{4}$ Para um histórico detalhado sobre este processo e acesso a vários documentos, consultar «https://sustainabledevelopment. un.org/topics/indicators〉.

${ }^{5}$ Em adição ao grupo de especialistas (IAEG) estabelecido pela Comissão de Estatística da ONU, não faltaram trabalhos paralelos, e alguns complementares, com a intenção de colaborar no processo de definição dos indicadores, como o grupo do Sustainable Development Solutions Networks, dirigido por Jeffrey Sachs, e o Partnership in Statistics for Development in the 21st Century (Paris21), que aglutina várias instituições como a ONU, o Banco Mundial e o FMI, entre outras, com o slogan "Melhorando a vida utilizando melhores estatísticas".
} 
agosto de $2015 .{ }^{6}$ A lista mostra claramente que a maioria das sugestões recebidas e, principalmente, aquelas levadas em consideração são as apresentadas pelas agências e organismos multilaterais. No entanto, a proposta ainda repete problemas presentes no primeiro rascunho e as negociações continuarão até o momento de sua aprovação, inclusive sobre a necessidade de se definir a periodicidade para a realização das avaliações de implementação da agenda.

A partir da definição oficial em 2016, haverá uma ampla campanha de divulgação dos Objetivos de Desenvolvimento Sustentável, a despeito da conjuntura econômica global bastante conturbada. Todavia, como firmou Alves (2015), “Os ODS apresentam uma boa intenção, mas vendem uma grande ilusão". No mesmo artigo, o autor comenta as vantagens e desvantagens de cada um dos 17 objetivos. Sem querer entrar nos detalhes de cada objetivo, cabe destacar que o crescimento demoeconômico continua sendo o fundamento da agenda pós-2015. Por exemplo, entre 2000 e 2015, nada foi feito para mudar a situação da gravidez indesejada e a falta de acesso aos métodos contraceptivos. Nos ODS a meta "Alcançar o acesso universal à saúde reprodutiva" foi repetida, mas com data limite de 2030. Nada foi reportado sobre o adiamento da meta \# 5b dos ODMs e pouco tem sido feito para que desta vez a universalização dos direitos reprodutivos seja uma realidade. A dinâmica demográfica mundial tem sido ignorada na formulação da agenda pós-2015.

Mas o mais grave é o apelo ao crescimento econômico como panaceia para todos os problemas sociais. O ODS \# 8 fala em crescimento econômico sustentado, sendo que o ícone que o representa tem uma seta apontando para cima. O ODS \# 12 diz: "Assegurar padrões de consumo e produção sustentáveis", mas não apresenta uma definição clara de sustentabilidade. Sintomaticamente, o símbolo utilizado no ícone de propaganda é o oito deitado, que representa o infinito. Mais contundente é o objetivo \# 8.1: "Sustentar o crescimento econômico per capita, de acordo com as circunstâncias nacionais e, em particular, pelo menos um crescimento anual de $7 \%$ do PIB nos países menos desenvolvidos". A ONU - pressionada pelo loby dos países pobres a favor do crescimento econômico e pelo loby dos países ricos contra a redistribuição da renda mundial - rendeu-se à lógica simplista de que o crescimento econômico é solução para os problemas sociais.

Pois bem, consideremos então o caso dos países mais pobres da África. As projeções demográficas apontam que a população da África Subsaariana, entre 2015 e 2100, deve aumentar de um bilhão para algo em torno de 3 a 5 bilhões de habitantes, com a média de 4 bilhões como o cenário mais provável. O PIB da África Subsaariana (em poder de paridade de compra) está estimado em US\$3,5 trilhões em 2015, com uma renda per capita de US\$ 3,8 mil, segundo dados do Fundo Monetário Internacional (FMI). Se a economia crescer $7 \%$ ao ano, a África Subsaariana terá um PIB 16 vezes maior em 40 anos, podendo chegar a US\$ 56 trilhões em 2055, com renda per capita de US\$22,4 mil em 2055. Este montante é superior aos PIBs atuais dos EUA, União Europeia e América Latina juntos. Se a taxa de 7\%

\footnotetext{
${ }^{6} \mathrm{O}$ documento com o conjunto de indicadores pode ser encontrado em «https://sustainabledevelo pment.un.org/content/ documents/7981List\%20of\%20Indicator\%20Proposals\%2011-8-2015.pdf〉.
} 
continuar por 80 anos, o PIB da África Subsaariana será de, no mínimo, US\$ 896 trilhões em 2100 (10 vezes superior ao PIB mundial de 2015). 0 que faltou explicar é como, neste quadro, garantir a sustentabilidade entre economia e meio ambiente.

Os formuladores dos ODS ignoraram o alerta feito pelos estudiosos da economia ecológica, que não cansam de repetir que é impossível manter o contínuo crescimento das atividades antrópicas no contexto incontornável do fluxo metabólico entrópico. Segundo Nicholas Georgescu-Roegen (1971), com base na segunda lei da termodinâmica - lei do aumento da entropia -, as atividades antrópicas ocorrem por meio do aumento de energia não utilizável para realizar trabalho. 0 crescimento da produção econômica resulta numa constante elevação de energia não aproveitável e do grau de desordem do sistema. Para o autor, há um constante aumento da entropia (e do caos) associado ao processo de produção de bens realizado pelo desenvolvimento. Herman Daly (2005) mostra que estamos em um "mundo cheio" e caminhando para um crescimento deseconômico. Outros estudiosos da economia ecológica, como Cechin e Veiga (2010), também reforçam o ponto de vista de Daly e Georgescu-Roegen, quando tratam da entropia e da impossibilidade de um crescimento econômico exponencial em um planeta finito.

O que mais interessa, portanto, é entender que a Terra é atravessada por um fluxo de energia extremamente significativo, que é finito e não crescente. Entra na forma de luz solar e sai como calor dissipado. Não haveria limite à expansão da economia se ela não fosse um subsistema aberto desse imenso sistema fechado. Mas se o pressuposto for inverso - e este é o ponto de partida da economia ecológica - então qualquer expansão da macroeconomia terá um custo. Qualquer aumento do subsistema exige algum tipo de contrapartida natural, fazendo com que tal decisão não possa ignorar seu 'custo de oportunidade' (CECHIN; VEIGA 2010, p. 36).

A despeito de todos objetivos e metas colocados nos temas ambientais, a natureza já se encontra degradada atualmente e a manutenção do ritmo de crescimento pode levar o planeta ao colapso ambiental, pois a ampliação das atividades antrópicas tem esbarrado nos limites do possível (RESENDE, 2013). Dessa forma, os ODS não conseguem, de fato, resolver as incompatibilidades do tripé da sustentabilidade e nem avança o suficiente na capacidade de governança global para reverter o rumo do modelo injusto de acumulação de riqueza.

\section{A 21a Conferência das Partes (COP-21)}

A Conferência para o Meio Ambiente e o Desenvolvimento (Rio/92) estabeleceu a Conferência Quadro das Nações Unidas para as Alterações Climáticas, que é um tratado internacional com o objetivo de estabilizar a concentração de gases do efeito estufa (GEE) na atmosfera em níveis que evitem o aquecimento perigoso da temperatura média do planeta. Ficou decidido que os atuais 194 países membros da Convenção do Clima reunir-se-iam anualmente nas reuniões chamadas Conferência das Partes (COP) para deliberar sobre as ações em defesa da atmosfera terrestre. A primeira Conferência das Partes (COP-1) 
ocorreu na cidade de Berlim, em 1995. Na COP-3, realizada na cidade de Kyoto, em 1997, foi aprovado o Protocolo de Kyoto, que, contudo, não conseguiu reverter as emissões de gases de efeito estufa (GEE).

A COP-21, que acontecerá em Paris, entre 30 de novembro e 11 de dezembro, terá como principal objetivo estabelecer um novo acordo global para diminuir a emissão de GEE, buscando limitar o aumento da temperatura global em $2^{\circ} \mathrm{C}$ até 2100 . Para tanto, o mundo só pode emitir 1.000 gigatoneladas (Gt) de $\mathrm{CO}_{2}$ (um trilhão de toneladas), entre 2012 e 2100. Porém, segundo Girardi (2015), o cálculo preliminar realizado em meados de setembro, com base nas INDCs (Contribuição Nacionalmente Determinada Pretendida, na sigla em inglês) - compromisso que os 196 países membros da convenção têm de propor até 1 을 de outubro para fundamentar o novo acordo climático global -, indicou que o mundo está perdendo a janela de oportunidade para resolver a crise do clima. Segundo dados do Painel Intergovernamental sobre Mudanças Climáticas (IPCC), o mundo emitiu $49 \mathrm{Gt}$ de GEE em 2010 e precisaria baixar para $11,3 \mathrm{Gt}$ de $\mathrm{CO}_{2}$ por ano até 2100 . Segundo Nobre $(2015$, p. 2):

As trajetórias mais seguras para a humanidade exigem redução de emissões da ordem de $60 \%$ a $70 \%$ até meados deste século. Em outras palavras, as emissões per capita devem convergir para não mais do que duas toneladas de $\mathrm{CO} 2$ equivalente (CO2e) em 2050. Atualmente, as emissões anuais per capita de EUA (18,6 t de CO2e), Rússia (15,8 t), Alemanha (10 t), China (7,9 t) e Brasil (7,5 t) estão acima da emissão per capita global (6,4 t). A soma das INDCs apresentadas até aqui, no entanto, é pouco auspiciosa: perfaz apenas $2 \%$ das reduções necessárias. Em 2030, cada americano estaria emitindo $17 \mathrm{t} \mathrm{de}$ CO2; cada russo, 13 t, cada alemão, 8,8 t; e cada chinês, 9,6 t. Sob a ótica das emissões per capita, percebe-se que a convergência para os valores desejáveis é muito lenta.

A organização Climate Action Tracker (2015) divulgou uma análise de 19 INDCs, que são documentos com as metas de cada país para reduzir as emissões de gases do efeito estufa. Os países avaliados respondem por $71 \%$ das emissões globais. A soma das propostas analisadas indica que, a despeito da boa vontade dos países, os resultados da COP-21 levariam a um aumento de temperatura de $2,7^{\circ} \mathrm{C}$ até o ano 2100 . A conclusão é que ainda não existem bases suficientes para limitar o aumento da temperatura a $2^{\circ} \mathrm{C}$ até o fim do século em relação ao período pré-industrial.

Porém, os eventos climáticos extremos, cada vez mais frequentes, tornam urgente evitar os piores cenários do aumento da temperatura média da Terra. 0 ano de 2014 foi o mais quente do planeta, desde que se iniciou o registro de temperaturas, em 1880, segundo dados da Administração Nacional Oceânica e Atmosférica dos Estados Unidos (NOAA, 2015). Segundo a mesma Agência, os anos de 2015 e 2016 devem bater novos recordes de aquecimento, agravado pelo fenômeno El Niño. Se nada for feito para se chegar a um acordo mais avançado, a COP-21 pode ser marcada pelo binômio: muito pouco, muito tarde. Se o clima ultrapassar os 2 graus centígrados de aquecimento - desde o início da Era Industrial -, as consequências serão danosas para o meio ambiente, a economia e a vida na Terra. 


\section{Considerações finais}

Em muitos aspectos a agenda internacional pós-2015 repete a receita de fazer mais do mesmo - crescimento econômico pelo crescimento - apenas com a tentativa de redução de danos ambientais e sociais. Pelo princípio da precaução, a humanidade deveria evitar continuar em sua marcha gananciosa pela dominação e exploração dos recursos naturais e de agressão à biodiversidade. Não faz sentido a corrida pelo crescimento econômico ilimitado se o rumo vai na direção de um precipício.

Vale a pena lembrar a pergunta de Celso Furtado, no livro 0 mito do desenvolvimento econômico, feita ainda nos idos de 1974, sobre o que aconteceria se o desenvolvimento econômico chegar efetivamente a se concretizar e se universalizar:

A resposta a essa pergunta é clara, sem ambiguidades: se tal acontecesse, a pressão sobre os recursos não renováveis e a poluição do meio ambiente seriam de tal ordem (ou alternativamente, o custo do controle da poluição seria tão elevado) que o sistema econômico mundial entraria necessariamente em colapso (FURTADO,1974, p. 19).

Dito de maneira clara: é impossível manter um crescimento econômico infinito em um planeta finito. Porém, existem pensadores cornucopianos, geralmente defensores do fundamentalismo de mercado (DIAMONDIS; KOTLER, 2012; RIFKIN, 2014), que consideram ser possível manter o modelo de crescimento, mas desmaterializando os bens de consumo, seja pelo crescimento da sociedade da informação e do conhecimento, seja pelo desacoplamento (decoupling) entre bens de consumo e recursos naturais.

A ideia do desacoplamento é tema central do Painel Internacional de Recursos da ONU, que busca estabelecer políticas que possibilitem dissociar os efeitos do crescimento econômico do uso dos recursos naturais e dos seus impactos ambientais. 0 próprio Painel de Recursos da ONU reconhece que o uso global per capita de materiais (biomassa, combustíveis fosseis, minerais metálicos e minerais não metálicos) continua crescendo, pois passou de seis para oito toneladas, entre 1970 e 2000, e chegou a dez toneladas, em 2010. Houve, portanto, aumento absoluto no uso dos materiais extraídos do meio ambiente. Mas também ocorreu crescimento relativo, pois a quantidade de material (kg) para produzir uma unidade de PIB (US\$) passou de 1,2 kg, em 2000, para 1,4 kg, em 2010 (UNEP, 2015). Além disso, o nível de reciclagem é muito baixo e os ganhos microeconômicos são minimizados pela ampliação da demanda agregada, em decorrência do efeito rebote e do Paradoxo de Jevons (SMIL, 2013).

Nesse contexto, os três grandes eventos da ONU em 2015, embora articulados e bem intencionados, não têm se mostrado capazes de dar um novo rumo ao modelo hegemônico de desenvolvimento, que continua sustentado na produção de mercadorias e na acumulação de capital. 0 modelo carece, por um lado, de sustentação ecológica e, por outro, de justiça distributiva em sua arquitetura social. 0 "ser humano" está sendo transformado, pela onipresente máquina de propaganda, em "ter humano" (TAVARES, 2010). 0 consumo assumiu ares de religião e, conforme mostra Gali (2014), o desenvolvimento sustentável 
se mostra incapaz de mudar o vício da dependência ao consumo conspícuo. Nesse quadro, em vez da continuidade do progresso civilizatório pregado pela agenda pós-2015 da ONU, o mundo pode ser vítima do seu próprio veneno, expresso no vício do consumicídio.

\section{Referências}

ALVES, J. E. D. Objetivos de Desenvolvimento Sustentável (ODS): boa intenção, grande ilusão. Ecodebate, 11/03/2015.

CARVALHO, P. G. M.; BARCELLOS, F. C. Os Objetivos de Desenvolvimento do Milênio - ODM: uma avaliação crítica. Sustentabilidade em Debate, v. 5, n. 3, p. 222-244, set./dez. 2014.

CAVENAGHI, S. Data revolution: is Latin America prepared and ready to engage? In: ANNUAL MEETING POPULATION ASSOCIATION OF AMERICA, 2015. San Diego. Program of the 2015 Annual Meeting of the Population Association of America. San Diego: PAA, 2015. Disponível em <http:// paa2015.princeton.edu/uploads/153763〉. Acesso em: 01 out. 2015.

CECHIN, A.; VEIGA, J. E. O fundamento central da economia ecológica. In: MAY, P. (Org.). Economia do meio ambiente: teoria e prática. 2. ed. Rio de Janeiro: Elsevier/Campus, 2010. p. 33-48.

CLIMATE ACTION TRACKER. INDCs lower projected warming to $2.7^{\circ} \mathrm{C}$ : significant progress but still above $2^{\circ} \mathrm{C}$. London: Climate Action Tracker, 1st October 2015.

CORREA, S.; ALVES, J. E. D. As Metas de Desenvolvimento do Milênio: grandes limites e oportunidades estreitas.Revista Brasileira de Estudos de População, v. 22, n. 1, p. 177-189, 2005.

CUNHA, J. M. P.; RODRIGUEZ-VIGNOLI, J. Urban growth and mobility in Latin America. In: CAVENAGHI, S. (Org.). Demographic transformations and inequalities in Latin America: historical trends and recent patterns. 1. ed. Rio de Janeiro: Alap, 2009. p. 25-64 (Serie Investigaciones, v. 8).

DALY, H. What is wrong with a zero interest rate? The Daly News. Center for the Advancement of the Steady State Economy, 17/09/2015.

Economics in a full world. Scientific American, September 2005.

DAVEY, B. Austerity and degrowth: dealing with the economic crisis and the ecological crisis together. Resilience, 13/08/2015.

DIAMANDIS, P.; KOTLER, S. Abundance: the future is better than you think. New York, London, Toronto, Sydney, New Delhi: Free Press, 2012.

ESCAMILLA, T. 200 million in Latin America at risk of poverty again. Oxfam, 30/09/2015.

FIP. Terceiro FfD: fracasso no Financiamento ao Desenvolvimento. Fórum Internacional das Plataformas Nacionais de ONGs, 11/08/2015.

FURTADO, C. 0 mito do desenvolvimento econômico. Rio de Janeiro: Paz e Terra, 1974.

GALI, J. M. Consumicídio: ensayo sobre el consumo (in)sostenible. Omniabooks, 2014.

GEORGESCU-ROEGEN, N. The entropy law and the economic process. Cambridge: Harvard University Press, 1971.

McGREAL, C. 70 years and half a trillion dollars later: what has the UN achieved? The Guardian, 07/09/2015.

MCKINSEY GLOBAL INSTITUTE. Winning the $\$ 30$ trillion decathlon: going for gold in emerging markets. 2012. 
NOAA. The recent global surface warming hiatus. May 2015.

NOBRE, C. Oportunidade histórica. Folha de S. Paulo, 20/08/2015.

OMS. 222 milhões de mulheres que não querem engravidar não têm acesso a contraceptivos. ONU Brasil, 07/03/2014.

PIETRICOVSKY, I. Caminhos percorridos da Rio 92 à Pós-2015. Inesc, 10/09/2014.

REIS, M. III Conferência FpD: quem paga a conta dos países mais pobres? Abong, 2015.

RESENDE, A. L. Os limites do possível: a economia além da conjuntura. São Paulo: PortfolioPenguin, 2013.

RIFKIN, J. The zero marginal cost society: the internet of things, the collaborative commons, and the eclipse of capitalism. Palgrave MacMillan, 2014.

SMIL, V. Making the modern world: materials and dematerialization. Sussex: Wiley, 2013.

TAVARES, F. Do ser humano ao ter humano. O comportamento do consumidor e a Teoria do Mosaico Fluído, 22/01/2010. Disponível em: 〈http://www.portaldomarketing.com.br/Artigos2/ Do_ser_humano_ao_ter_humano_o_comportamento_do_consumidor_e_a_teoria_do_mosaico_ fluido.htm>.

UN. The millennium development goals report 2015. New York: United Nations, 2015.

UNEP. The International Resource Panel (IRP) United Nations Environment Programme, 2011.

\section{Sobre 0 autor}

José Eustáquio Diniz Alves é doutor em Demografia pelo Centro de Desenvolvimento e Planejamento Regional - Cedeplar da Universidade Federal de Minas Gerais -UFMG, com pós-doutorado no Núcleo de Estudos de População - Nepo, da Universidade Estadual de Campinas - Unicamp. Professor titular do Programa de Pós-graduação em População, Território e Estatísticas Públicas da Escola Nacional de Ciências Estatísticas - Ence, do Instituto Brasileiro de Geografia e Estatística - IBGE.

\section{Endereço para correspondência}

José Eustáquio Diniz Alves

Escola Nacional de Ciências Estatísticas

Rua André Cavalcanti, 106, sala 502, Bairro de Fátima

20231-050 - Rio de Janeiro-RJ, Brasil

Recebido para publicação em 20/09/2015 Recomendado para publicação em 26/10/2015

Aceito para publicação em 30/10/2015 